\title{
Author Correction: Accurate Micro-Tool Manufacturing by Iterative Pulsed-Laser Ablation
}

\author{
Maximilian Warhanek ${ }^{1}$ (D) Josef Mayr $^{2}$. \\ Christian Dörig $^{1} \cdot$ Konrad Wegener $^{1}$
}

Published online: 9 November 2017

C Springer Science+Business Media, LLC, part of Springer Nature 2017

Author Correction: Lasers Manuf. Mater. Process. (2017)

https://doi.org/10.1007/s40516-017-0046-y

The original version of this article unfortunately contained a mistake. The name of the 3 rd author on the published version of the article was wrong. With this, the original article was corrected and the correct name of the 3rd author is now presented in here.

The online version of the original article can be found at https://doi.org/10.1007/s40516-017-0046-y

Maximilian Warhanek

warhanek@iwf.mavt.ethz.ch

1 Institute of Machine Tools and Manufacturing, ETH Zurich, Leonhardstrasse 21, 8092 Zürich, Switzerland

2 inspire AG, Technoparkstrasse 1, 8005 Zürich, Switzerland 